\title{
Effects of disodium cantharidinate on dendritic cells of patients with bladder carcinoma
}

\author{
GUANG-HUI ZANG ${ }^{1}$, RUI LI ${ }^{2}$, RONG-SHENG ZHOU ${ }^{1}$, LIN HAO ${ }^{1}$, HOU-GUANG HE ${ }^{1}$, \\ WEN-DAZHANG ${ }^{1}$, YANG DONG ${ }^{1}$ and CONG-HUI HAN ${ }^{1}$ \\ ${ }^{1}$ Department of Urology, Xuzhou Central Hospital, Xuzhou, Jiangsu 221009; ${ }^{2}$ Department of Urology, Tongji Hospital, \\ Tongji Medical College, Huazhong University of Science and Technology, Wuhan, Hubei 430014, P.R. China
}

Received April 10, 2017; Accepted September 6, 2017

DOI: $10.3892 / \mathrm{ol} .2017 .7589$

\begin{abstract}
The present study explored the effects of disodium cantharidinate (DC) on the peripheral blood-derived dendritic cells of patients with bladder carcinoma. The peripheral blood mononuclear cells from the 15 cases of urinary bladder carcinoma of middle and advanced stage were separated, and dendritic cells were prepared. The morphological changes of dendritic cells were observed. Flow cytometry was used to detect the expression levels of CD1a and CD83 on dendritic cell surface. MTT assay was utilized to measure the proliferation ability of allogeneic lymphocyte stimulated by DC. Annexin V-FITC/propidium iodide (PI) double staining flow cytometry method was carried out to detect cell apoptosis after treatment with DC. The changes in caspase-3 and PARP expression levels were investigated by western blot method. The high-dose DC resulted in a significant increase in the expressions of dendritic cell phenotyptic molecules CDla and CD83 as compared to control group. In addition, the proliferation index of allogenic lymphocyte stimulated by DC was significantly higher than that of control group. Moreover, MTT assay showed significant inhibition of the growth of BIU-87 cells. After $24 \mathrm{~h}$ of DC treatment, double staining flow cytometry confirmed the ability of DC to induce cell apoptosis. Further, western blot method showed a significant elevation of caspase-3 and PARP protein expression after DC treatment. In conclusion, DC treatment could induce dendritic cell maturation of patient with carcinoma of urinary bladder and promote its functional changes. Furthermore, DC was able to inhibit the proliferation of cell BIU-87 and also has the ability to induce cell apoptosis.
\end{abstract}

\section{Introduction}

Bladder tumor is one of the most common tumors, featuring high incidence rate, high recurrence rate and low-grade

Correspondence to: Dr Cong-Hui Han, Department of Urology, Xuzhou Central Hospital, 199 Jiefang South Road, Xuzhou, Jiangsu 221009, P.R. China

E-mail:ma0420040@163.com

Key words: disodium cantharidinate, dendritic cells, BIU-87, apoptosis malignancy (1). The main symptom of patients with carcinoma of urinary bladder is hematuresis. Clinically, radiography and cystoscopy are often taken as the diagnostic methods of carcinoma of urinary bladder (2). The patients with carcinoma of urinary bladder could be divided into superficial bladder cancer and invasive bladder cancer. Superficial bladder cancer has the features of high recurrence rate and low metastasis rate, while the features of invasive bladder cancer are high invasion and metastasis rate (3).

Dendritic cell is a kind of antigen presenting cell that plays a key role in the process of tumor immunity (4). Further, studies in the recent past revealed that a decrease in the dendritic cells could affect immune response of lymphocytes, leading to immune tolerance of organism (5-7). As a consequence, cancer cells would escape from the organism immune system. Thus, dendritic cells play an important role in the process of tumor occurrence, development and metastasis (5). The study confirmed that dendritic cells have a close relation with carcinoma of urinary bladder, which could involve in the treatment of carcinoma of urinary bladder. Moreover, dendritic cells are also reported as makers of urinary bladder carcinoma $(6,7)$.

Disodium cantharidinate (DC) is a ramification of cantharidin, which is being used clinically for the cure of liver cancer and stomach cancer. DC has the characteristics of low virulence and irritability as compared to lead compound cantharidin (8-11). The antitumor mechanisms of DC are complicated and multiple. The different approaches used by DC against carcinogenesis include interdicting cell cycle, inducing cell apoptosis, inhibiting the invasion/metastasis of tumor cells and improving the immunity of the organism (12-14). In the present study, the effect of DC on the maturation and function of peripheral blood-derived dendritic cells in urinary bladder cancer patients was studied, as these cells are crucial for immune response against tumors. We provide research basis for the clinical application of DC for the patients with carcinoma of urinary bladder.

\section{Materials and methods}

Materials. rh-GM-CSF and rh-IL-4 were procured from R\&D Systems (Minneapolis, MN, USA). Mouse anti-human CDla and CD83 mococlonal antibodies were labeled by FITC from Invitrogen (Carlsbad, CA, USA) (dilution, 1:500; 
cat. nos. 11-0015-42 and 11-0839-42). Mouse anti-human caspase-3, PARP, GAPDH primary polyclonal antibody (dilution, 1:1,000; cat. nos. ABP57612, ABP57383 and ABP57259) and goat anti-mouse HRP-labeled second polyclonal antibody (dilution, 1:2,000; cat. no. A21010) were procured from AmyJet Scientific Co., Ltd. (Wuhan, China). Ficoll paque plus and lymphocyte separation medium were obtained from Amersham Biosciences Corp. (Piscataway, NJ, USA). RPMI-1640 culture medium and fetal calf serum were provided by HyClone Laboratories (Logan, UT, USA). BCA protein assay kit and Annexin V-FITC apoptosis detection kit were procured from Beyotime Institute of Biotechnology (Nantong, China).

Dendritic cell culture in vitro and medication. Fifteen patients with carcinoma of urinary bladder and 10 healthy persons were selected as study subjects. Twenty milliliters venous blood was extracted from each person, and peripheral blood mononuclear cells were separated by Ficoll paque plus. Further, lymphocyte separation medium was cultured for $2 \mathrm{~h}$ under the condition of $37^{\circ} \mathrm{C}$ and $5 \% \mathrm{CO}_{2}$. Suspension cells were removed by washing to obtain adherent cells. Then medium RPMI-1640 that contained GM-CSF (1,000 IU/ml), IL-4 (500 IU/ml) and $10 \%$ autoserum was applied to culture, which was changed to half after every $24 \mathrm{~h}$. The fifth day, the cultured cells were divided into groups as follows: Control group; low-dose DC group $(0.01 \mu \mathrm{g} / \mathrm{ml})$; middle-dose DC group $(0.05 \mu \mathrm{g} / \mathrm{ml})$; highdose DC group $(0.25 \mu \mathrm{g} / \mathrm{ml})$; healthy people group. Related detections were conducted for the eighth day after cells were collected.

Expression of CDla and CD83 of dendritic cells by flow cytometry. Cells from the eighth day were collected. The fluorescent antibodies CD1a and CD83 were then added, which was followed by incubation for $30 \mathrm{~min}$ under room temperature and darkroom. Precooling phosphate buffer $(2 \mathrm{ml})$ was then added. At last, flow cytometry was applied to detect the expression levels of CD1a and CD83 on the surface of dendritic cells from each group.

Influence of DC on lymphocyte proliferation of dendritic cells detected by 3-(4,5-dimethylthiazol-2-yl)-2,5-diphenyltetrazolium bromide (MTT). Venous blood of healthy people was extracted and separated to monocyte that was cultivated under the condition of $37^{\circ} \mathrm{C}$ and $5 \% \mathrm{CO}_{2}$. After $2 \mathrm{~h}$, the cells that were not adherent to the walls, were absorbed to obtain lymphocytes. Dendritic cells in each group of the eighth day were collected and incubated for $30 \mathrm{~min}$ by mitomycin $\mathrm{C}$ $(50 \mathrm{~g} / \mathrm{ml})$. The cell density was adjusted to $1 \times 10^{7} /$ liter dendritic cells and lymphocyte were mixed by the proportion of 1:10. The mixed cells were gathered on 96-well plates and were cultured for $48 \mathrm{~h}$. MTT method was used to test the cell activity. Absorbance values on the position of $570 \mathrm{~nm}$ were measured to calculate the stimulation index of lymphocytes according to the formula, stimulation index $=$ experimental group OD value/control OD value.

Inhibition effects of DC on urinary bladder carcinoma BIU-87 cells. BIU-87 was cultivated by RPMI-1640 that contained $10 \%$ fetal calf serum under the condition of $37^{\circ} \mathrm{C}$ and $5 \% \mathrm{CO}_{2}$. There were 3 groups viz. control group (without drugs), $10 \mu \mathrm{g} / \mathrm{ml}$ DC group and $20 \mu \mathrm{g} / \mathrm{ml}$ DC group. Six pores were set in each group and MTT treatment fluid was added 12, 24, 36 and $48 \mathrm{~h}$ after cultivation. The absorbance values were recorded at $570 \mathrm{~nm}$ and the enzyme-linked immunosorbent assay (ELISA) was used to calculate cell viability.

Influence of DC on apoptosis of urinary bladder carcinoma BIU-87 cells detected by Annexin V-propidium iodide (PI) double staining method. On the basis of the groups in 2.5, BIU-87 of logarithmic phase was inoculated to 6 pore plates respectively, after $24 \mathrm{~h}$ of drug function. The cells were collected from digestion and centrifugation. Binding buffer solution $(0.3 \mathrm{ml})$ was added and blended. Annexin $\mathrm{V}$ of $5 \mu \mathrm{l}$ and PI of $5 \mu \mathrm{l}$ were added to each test sample and incubated for $15 \mathrm{~min}$ under room temperature. Binding buffer solution $(0.2 \mathrm{ml})$ was refilled. Flow cytometry was applied to detect cell apoptosis.

Statistical analysis. SPSS 13.0 (SPSS, Inc., Chicago, IL, USA) analyzed the experimental data. One-way ANOVA was applied to analyze the data. $\mathrm{P}<0.05$ is considered to indicate a statistically significant difference.

\section{Results}

Expression of CDla and CD83 of dendritic cells by flow cytometery. The image result of inverted microscope is shown in Fig. 1. The cells of DC group were larger as compared to control group. The cells of high-dose DC group (Fig. 1D) showed protuberance and was shaped as a branch, which was similar to the cellular morphology of healthy people group (Fig. 1E). The results of flow cytometry detection are shown in Fig. 2. Compared with control group, CD83 and CDla of DC treatment group increased significantly. In addition, the expression levels of CD83 and CDla of high-dose DC group were high but the difference had no statistical significance.

Detection of proliferation ability of allogeneic lymphocyte stimulated by $D C$. The proliferation index of allogenic lymphocyte stimulated by DC was significantly higher than that of control group (Fig. 3). Besides, different dose of DC in each group, the proliferation index of lymphocyte stimulated by DC in the high-dose group was the highest.

Inhibition effects of DC detected by MTT. The cell viability of each medication administration group reduced to different extent in comparison with control group (Fig. 4). The inhibition effect of drug increased significantly with increase in the concentration of DC.

Influence of DC on apoptosis of urinary bladder carcinoma BIU-87 cells (detected by Annexin V-PI double staining method). Compared with control group, the apoptosis rate of DC groups dramatically increased, and the difference was statistically significant $(\mathrm{P}<0.01)$. So, this result demonstrated that DC could induce BIU-87 apoptosis (Fig. 5).

Changes of caspase-3 and PARP protein expression detected by western blot method. Compared with control group, caspase- 3 and PARP protein expression of BIU- 87 from DC 


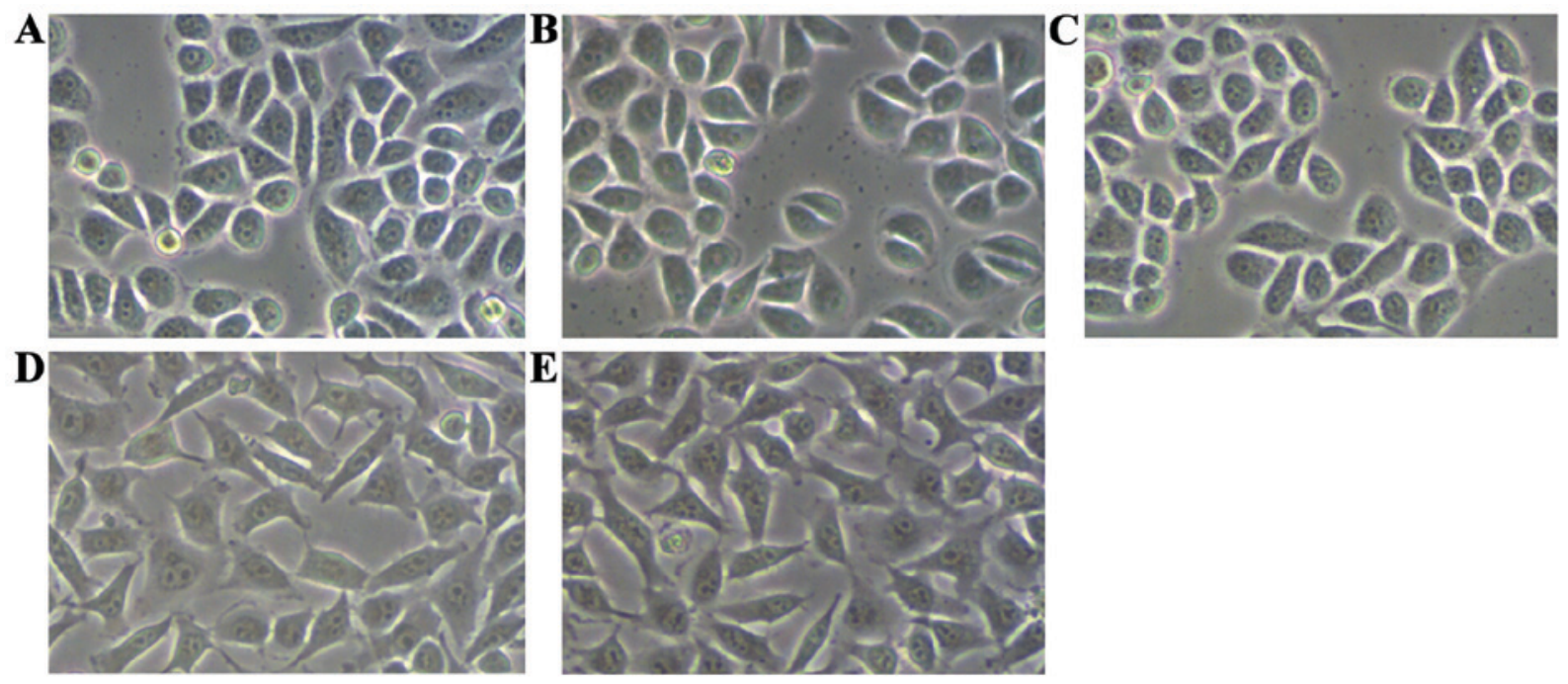

Figure 1. Morphology of dendritic cells (x400): (A) Control; (B) low-dose; (C) middle-dose; (D) high-dose; (E) healthy.

$\mathbf{A}$

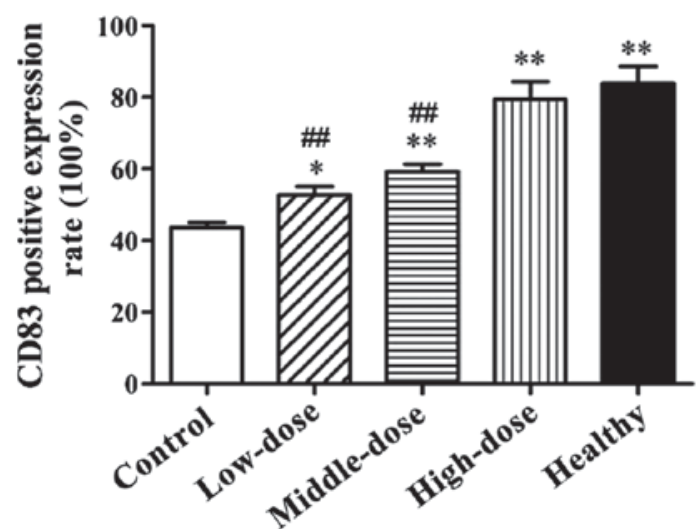

B

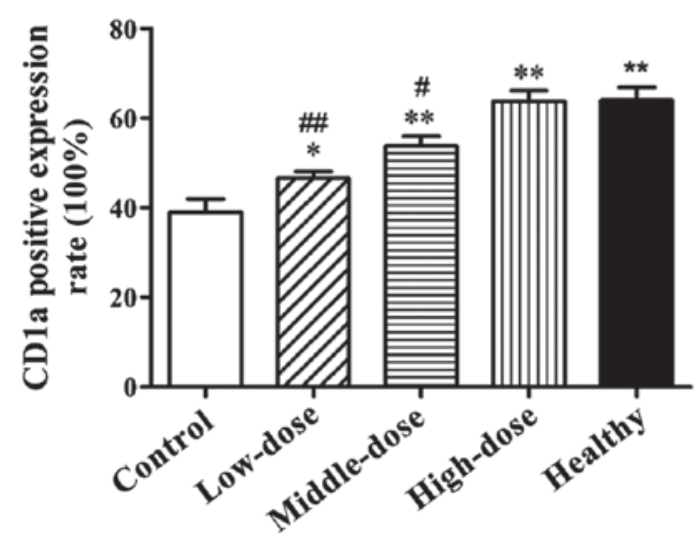

Figure 2. Expression of CD83 and CD1a in dendritic cells. " $\mathrm{p}<0.05$ and ${ }^{* *} \mathrm{p}<0.01$ compared with control group; ${ }^{\#} \mathrm{p}<0.05$ and ${ }^{\# \#} \mathrm{p}<0.01$ compared with healthy group.

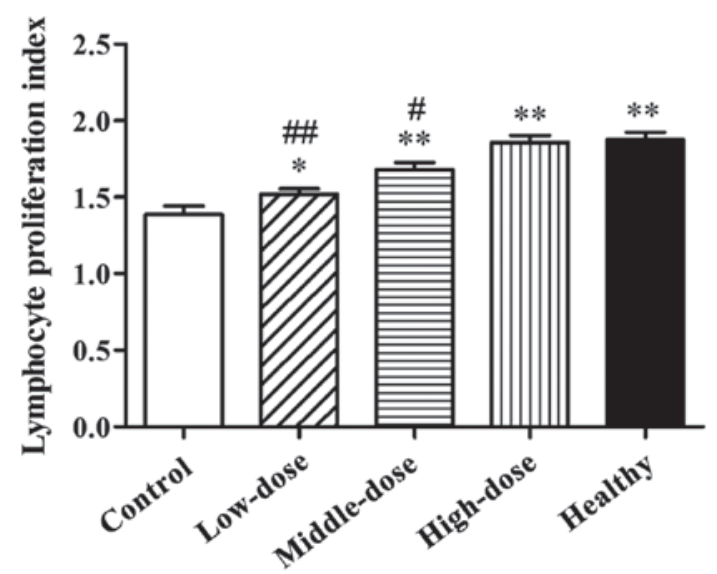

Figure 3. Cell proliferation of allogenic lymphocyte stimulated by disodium cantharidinate. " $\mathrm{p}<0.05$ and ${ }^{* *} \mathrm{p}<0.01$ compared with control group; ${ }^{*} \mathrm{p}<0.05$ and ${ }^{\# \#} \mathrm{p}<0.01$ compared with healthy group.

groups were significantly enhanced (Fig. 6) and the difference was statistically significant $(\mathrm{P}<0.01)$.

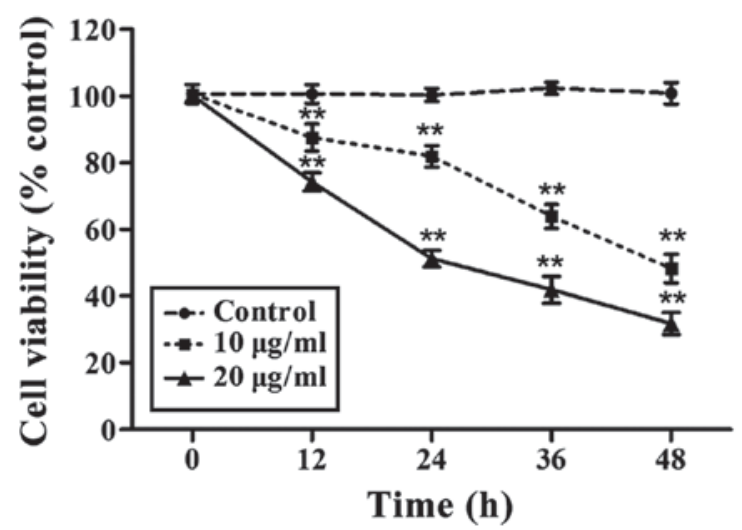

Figure 4. Cell viability treated by different concentrations of disodium cantharidinate, detected by 3-(4,5-dimethylthiazol-2-yl)-2,5-diphenyltetrazolium bromide (MTT) assay. ${ }^{* *} \mathrm{p}<0.01$ compared with control group.

\section{Discussion}

Carcinoma of urinary bladder is one of the most common tumors, which is mainly treated by the operation that reserves 


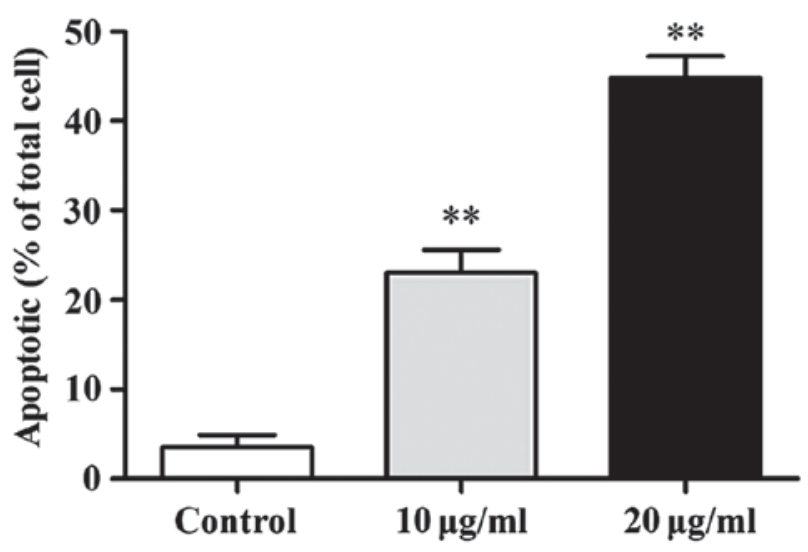

Figure 5. Apoptosis of different treatments of groups detected by flow cytometry. ${ }^{* *} \mathrm{p}<0.01$ compared with control group.

bladder in clinic. However, this therapeutic method may result in incomplete excision, as the recurrence rate of a half of patients is extremely high. At present, to solve this malpractice, drug therapy of intravesical instillation was applied to the patients after operation in clinic, but drug resistance is often associated with bladder tumor.

DC has not only antineoplastic activity but also has ability to affect the immune function of organism. The molecular weight of DC is small enough to enter cells. It could also improve the immunity of patients and make the antitumor effect stronger. Currently, the combination of DC and other antitumor drugs in clinic is mainly applied for the treatment of lung cancer, stomach cancer and old-aged bladder cancer (15-17). DC has the ability to improve the immune function of organism, by increasing the number of leucocytes so as to stimulate the secretion of cytokines $(18,19)$. Furthermore, the specific molecule on the surface of dendritic cell membrane could combine with the corresponding ligand of lymphocyte surface; as a result, antigen-specificity $\mathrm{T}$ cells are activated and proliferated, which in turn activates immune response (20-22). Multiple approaches to produce a large number of dendritic cells have been developed, and the sources mainly include marrow, cord blood and peripheral blood, among which peripheral blood is the most common approach (23).

In the present study, CDla revealed the number of dendritic cells, in addition, CD83 acted as a marker for the maturity of dendritic cells $(24,25)$. The results of this experiment proved that the surface of cultured cells produced protuberance and shape as branch after DC and dendritic cells were incubated together. At the same time, the expressions of CDla and CD80 on the surface of dendritic cells dramatically increased. The dendritic cells in high-dose DC group were compared with that of healthy group, and the difference had no statistical significance. Furthermore, MTT method was applied to detect the proliferation ability of lymphocyte stimulated by DC. The results showed that DC could improve the proliferation ability of lymphocytes, which suggested that DC could improve the immunity of patients.

The change of intercellular environment brings about emergency reaction of cells leading to self-destructing death of cells, called apoptosis. Multiple genes are involved in the whole process of cell apoptosis, among which caspase-3 plays a key role. When caspase-3 is activated, cells enter into an irreversible apoptosis process. Moreover, most of apoptosis induced by multiple factors are through caspase-3 (26).

Further, MTT method demonstrated that DC could significantly inhibit the growth of BIU-87, showing dose- and time-dependence. Annexin V-PI double staining method testified that DC could induce BIU-87 apoptosis. Further the influence of DC on apoptin caspase-3 and PARP expressions was also noted. As a result, in comparison with control group, caspase-3 and PARP protein expression of BIU-87 in DC groups increased, to promote BIU-87 cell apoptosis.

To sum up, on the one hand, DC could promote the maturation of dendritic cells for the patients with carcinoma of urinary bladder and enhance the proliferation of lymphocytes stimulated by dendritic cells. On the other hand, it could inhibit the proliferation of bladder cell BIU-87 by induction of apoptosis. This study provides a new strategy for the clinical application of DC during urinary bladder carcinoma.

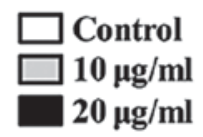

Control $10 \mu \mathrm{g} / \mathrm{ml} 20 \mu \mathrm{g} / \mathrm{ml}$

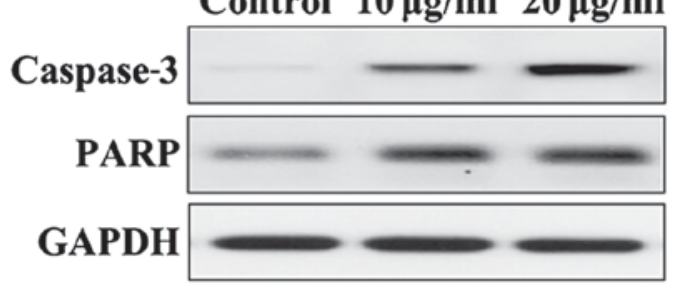

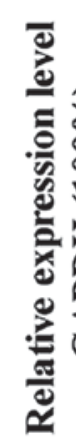

Figure 6. Caspase-3 and PARP protein expression detected by western blot analysis. ${ }^{* *} \mathrm{p}<0.01$ compared with the control group. 


\section{Acknowledgements}

The present study was funded by the Innovative and Entrepreneurial Doctor Project of Jiangsu Province (ZXYYSCBS-201703), the Top Six Talents Project of Jiangsu Province (2015-WSW-078) and the National Natural Science Foundation of China (81774089).

\section{References}

1. Trinchieri G and Sher A: Cooperation of Toll-like receptor signals in innate immune defence. Nat Rev Immunol 7: 179-190, 2007.

2. Kawai T and Akira S: TLR signaling. Semin Immunol 19: 24-32, 2007.

3. Krieg AM: Therapeutic potential of Toll-like receptor 9 activation. Nat Rev Drug Discov 5: 471-484, 2006.

4. Inaba K, Pack M, Inaba M, Sakuta H, Isdell F and Steinman RM: High levels of a major histocompatibility complex II-self peptide complex on dendritic from the T cell areas of lymph node. J Exp Med 186: 665-672, 1997.

5. Pirtskhalaishvili G, Shurin GV, Gambotto A, Esche C, Wahl M, Yurkovetsky ZR, Robbins PD and Shurin MR: Transduction of dendritic cells with Bcl-xL increases their resistance to prostate cancer-induced apoptosis and antitumor effect in mice. J Immunol 165: 1956-1964, 2000.

6. Inoue K, Yamashita A, Yamashita M, Morioka M, Fujita Y and Terao N: Distribution of S-100 protein-positive dendritic cells inside the cancer nest and expression of HLA-DR antigen and blood group antigen on the cancer cell in transitional cell carcinoma of the urinary bladder - in relation to tumor progression and prognosis. Nihon Hinyokika Gakkai Zasshi 85: 495-503, 1994 (In Japanese).

7. Troy AJ, Davidson PJ, Atkinson CH and Hart DN: CD1a dendritic cells predominate in transitional cell carcinoma of bladder and kidney but are minimally activated. J Urol 161: 1962-1967, 1999.

8. Wang CC, Wu CH, Hsieh KJ, Yen KY and Yang LL: Cytotoxic effects of cantharidin on the growth of normal and carcinoma cells. Toxicology 147: 77-87, 2000.

9. Efferth T, Davey M, Olbrich A, Rücker G, Gebhart E and Davey R: Activity of drugs from traditional Chinese medicine toward sensitive and MDR1- or MRP1-overexpressing multidrugresistant human CCRF-CEM leukemia cells. Blood Cells Mol Dis 28: 160-168, 2002.

10. Kok SH, Hong CY, Kuo MY, Lee CH, Lee JJ, Lou IU, Lee MS, Hsiao M and Lin SK: Comparisons of norcantharidin cytotoxic effects on oral cancer cells and normal buccal keratinocytes. Oral Oncol 39: 19-26, 2003.

11. McCluskey A, Ackland SP, Bowyer MC, Baldwin ML, Garner J, Walkom CC and Sakoff JA: Cantharidin analogues: Synthesis and evaluation of growth inhibition in a panel of selected tumour cell lines. Bioorg Chem 31: 68-79, 2003.

12. Verma AK and Prasad SB: Changes in glutathione, oxidative stress and mitochondrial membrane potential in apoptosis involving the anticancer activity of cantharidin isolated from redheaded blister beetles, Epicauta hirticornis. Anticancer Agents Med Chem 13: 1096-1114, 2013

13. Li W, Xie L, Chen Z, Zhu Y, Sun Y, Miao Y, Xu Z and Han X: Cantharidin, a potent and selective PP2A inhibitor, induces an oxidative stress-independent growth inhibition of pancreatic cancer cells through G2/M cell-cycle arrest and apoptosis. Cancer Sci 101: 1226-1233, 2010.
14. Chen X, Qiu J, Yang D, Lu J, Yan C, Zha X and Yin Y: MDM2 promotes invasion and metastasis in invasive ductal breast carcinoma by inducing matrix metalloproteinase-9. PLoS One 8: e78794, 2013

15. Zhan YP, Huang XE, Cao J, Lu YY, Wu XY, Liu J, Xu X, Xu L, Xiang J and Ye LH: Clinical study on safety and efficacy of Qinin ${ }^{\circledR}$ (cantharidin sodium) injection combined with chemotherapy in treating patients with gastric cancer. Asian Pac J Cancer Prev 13: 4773-4776, 2012.

16. Liu ZY, Qiu HO, Yuan XJ, Ni YY, Sun JJ, Jing W and Fan YZ: Suppression of lymphangiogenesis in human lymphatic endothelial cells by simultaneously blocking VEGF-C and VEGF-D/ VEGFR-3 with norcantharidin. Int J Oncol 41: 1762-1772, 2012.

17. Shou LM, Zhang QY, Li W, Xie X, Chen K, Lian L, Li ZY, Gong FR, Dai KS, Mao YX, et al: Cantharidin and norcantharidin inhibit the ability of MCF-7 cells to adhere to platelets via protein kinase $\mathrm{C}$ pathway-dependent downregulation of $\alpha 2$ integrin. Oncol Rep 30: 1059-1066, 2013.

18. Kunitani H, Shimizu Y, Murata H, Higuchi K and Watanabe A: Phenotypic analysis of circulating and intrahepatic dendritic cell subsets in patients with chronic liver diseases. J Hepatol 36: 734-741, 2002.

19. Szabolcs P, Moore MA and Young JW: Expansion of immunostimulatory dendritic cells among the myeloid progeny of human $\mathrm{CD} 34^{+}$bone marrow precursors cultured with c-kit ligand, granulocyte-macrophage colony-stimulating factor, and TNF-alpha. J Immunol 154: 5851-5861, 1995.

20. Rodríguez-Fernández JL and Corbí AL: Adhesion molecules in human dendritic cells. Curr Opin Investig Drugs 6: 1103-1111, 2005.

21. Anguille S, Smits EL, Lion E, van Tendeloo VF and Berneman ZN: Clinical use of dendritic cells for cancer therapy. Lancet Oncol 15: e257-e267, 2014.

22. Collins LE, DeCourcey J, Soledad di Luca M, Rochfort KD and Loscher CE: An emerging role for SNARE proteins in dendritic cell function. Front Immunol 6: 133-139, 2015.

23. Schmitt N and Ueno H: Regulation of human helper T cell subset differentiation by cytokines. Curr Opin Immunol 34: 130-136, 2015.

24. Rouard H, Léon A, Klonjkowski B, Marquet J, Tennezé L, Plonquet A, Agrawal SG, Abastado JP, Eloit M, Farcet JP, et al: Adenoviral transduction of human 'clinical grade' immature dendritic cells enhances costimulatory molecule expression and T-cell stimulatory capacity. J Immunol Methods 241: 69-81, 2000.

25. Seager Daneiger J, Lutz M, Hama S, Cruz D, Castrillo A and Lazaro J, Phillips R, Prernack B and Berliner J: Method for large scale isolation, culture and cryopreservation of human monocytes suitable for ehemotaxis, cellular adhesion assays, maerophage and dendritic eell differentiation. J Immunol Methods 288: 123-134, 2004

26. Li Z, Jo J, Jia JM, Lo SC, Whitcomb DJ, Jiao S, Cho K and Sheng M: Caspase-3 activation via mitochondria is required for long-term depression and AMPA receptor internalization. Cell 141: 859-871, 2010. International (CC BY-NC-ND 4.0) License. 